\title{
Comparison of Methane Control Methods in Polish and Vietnamese Coal Mines
}

\author{
Marek Borowski ${ }^{1,}{ }^{*}$, and Zbigniew Kuczera ${ }^{1}$ \\ ${ }^{1}$ AGH University Science and Technology, Faculty of Mining and Geoengineering, \\ A. Mickiewicza Av. 30, 30-059 Krakow, Poland
}

\begin{abstract}
Methane hazard often occurs in hard coal mines and causes very serious accidents and can be the reason of methane or methane and coal dust explosions. History of coal mining shows that methane released from the rock mass to the longwall area was responsible for numerous mining disasters. The main source of methane are coal deposits because it is autochthonous gas and is closely related with carbonification and forming of coal deposits. Degree of methane saturation in coal deposits depends on numerous factors; mainly on presence or lack of insulating layers in cover deposit that allow or do not on degasification and easily methane outflow into surroundings. Hence in coal mining there are coal deposits that contain only low degree of methane saturation in places where is lack of insulating layers till high in methane coal deposits occurring in insulating claystones or in shales. Conducting mining works in coal deposits of high methane hazard without using of special measures to combat (ventilation, methane drainage) could be impossible. Control of methane hazard depends also on other co-occuring natural dangers for which used preventive actions eliminate methane hazard. Safety in mines excavating coal deposits saturated with methane depends on the correct estimation of methane hazard, drawn up forecasts, conducted observations, hazard control as well as undertaken prevention measures. Methane risk prevention includes identification and control methods of methane hazards as well as means of combating the explosive accumulation of methane in longwall workings. The main preventive actions in underground coal mines are: effective ventilation that prevents forming of methane fuses or placed methane accumulation in headings ventilated by airflow created by main fans and in headings with auxiliary ventilation, methane drainage using drain holes that are drilled from underground headings or from the surface, methanometry control of methane concentration in the air; location of the sensors is defined by law, additional ventilation equipment used in places of lower intensity of ventilation and places where methane is concentrated. Key words - methane hazard, methods of methane control, methane risk prevention, methane drainage, methanometry control.
\end{abstract}

\section{Introduction}

History of coal mining shows that methane released from the rock mass to the longwall area was responsible for numerous mining disasters. Especially the methane hazard causes very serious accidents and can be the reason of methane or methane and coal dust explosions.

\footnotetext{
Corresponding author: marek.borowski@agh.edu.pl
} 
The main source of methane are coal deposits because it is autochthonous gas and is closely related with carbonification and forming of coal deposits. Degree of methane saturation in coal deposits depends on numerous factors.

Mining activity in coal deposits of high methane content without using of special measures to combat could be impossible. Safety in mines excavating coal deposits saturated with methane depends on the correct estimation of methane content in coal seams, drawn up forecasts of methane emission, hazard control as well as undertaken prevention measures.

Methane risk prevention includes identification and control methods of methane hazards as well as means of combating the explosive accumulation of methane in longwall workings. The main preventive actions in underground coal mines are [2, 5]:

- ventilation that prevents forming methane accumulation in roadways,

- methane drainage using boreholes that are drilled from underground or surface,

- methanometry control of methane concentration in the air,

- additional ventilation equipment used in places where methane is concentrated.

The amount of released methane is closely related with the range of mining activity, actual exploitation as well as development works.

Safe work conditions can be provided only through properly adjusted actions. Selection of prevention method is closely related to longwall ventilation systems. Ventilation system should be depended on predicted methane bearing capacity of longwall workings and chosen at the design stage.

In this article the comparison has been carried out between the actions taken in Polish and Vietnamese coal mines in order to prevent of methane hazard.

\section{Longwall ventilation system}

The amount of released methane is closely linked to exploitation of coal seams. Ventilation is aimed at methane diluting to the level defined for ensuring safe work. When ventilation is not sufficient then methane drainage systems are used. In the case the methane concentration in the longwall face is high, the use of additional preventive measures are recommended.

In Polish coal mines the longwall retreat system is commonly used. The Vietnamese coal mines employ both longwall and shortwall mining systems. The mining system needs the selection of longwalls ventilation system. The choice of ventilation should depend on estimated natural hazards beginning with the design stage of the project. The co-occurance of methane emission, spontaneous fires and temperature hazards are decisive issues for the sector.

Presently ventilation systems of retreat mining are most frequently used (Fig. 1) [5]:

- system U,

- system Y: return side system or bleeder system.

$\mathrm{U}$ ventilation system is widely used in Polish coal mines, however under conditions of high methane hazard Y ventilation system is commonly employed. The Vietnamese coal mines use $U$ ventilation system. Due to lower productivity of ventilation system in Vietnamese mines the auxiliary ventilation (i.e. booster fan) is used in longwall system. An example of its use is presented in Figure 2.

The $U$ ventilation system is generally used in longwalls with low-predicted methane emission; with high methane emission the system can be used only including effective methane drainage. In case of spontaneous fire in goaf the system makes its containing difficult. The system is irrelevant in extremely tough conditions, when there is serious methane hazard with limited face advance rate and spontaneous combustion of coal occurs. It causes difficulties 
in effective combating of coexisting mining hazards. It is necessary to use the supplementary protection measures and ventilation equipments however, they do not achieve expected results.

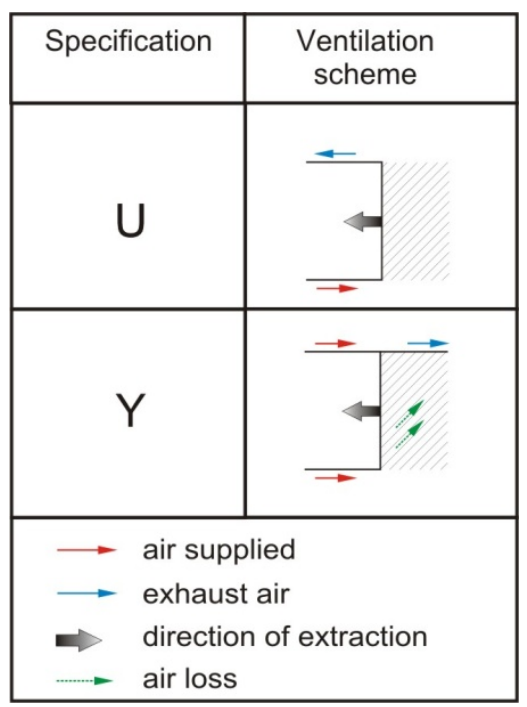

Fig. 1. Ventilation systems in hard coal mines: $U$ ventilation system and $Y$ ventilation system (bleeder system)

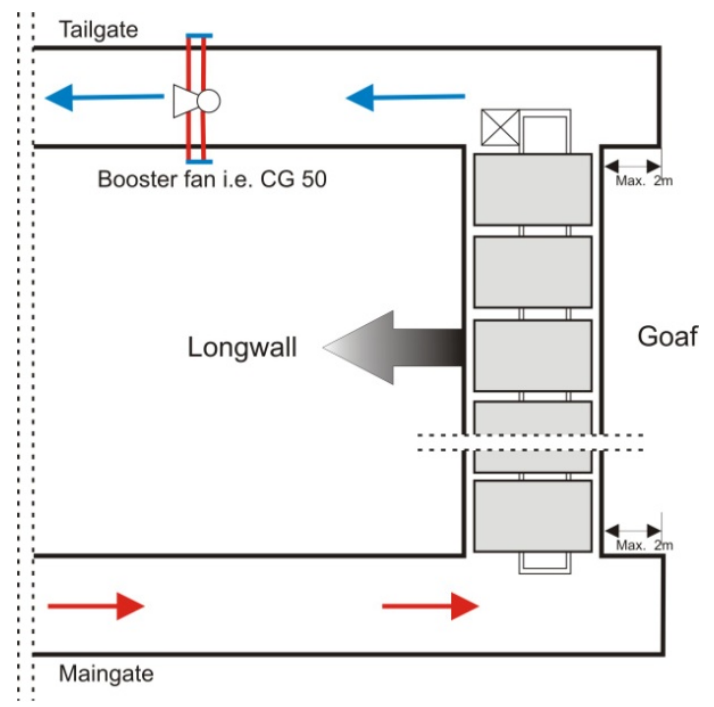

Fig. 2. Example of auxiliary ventilation use in $U$ ventilation system for longwall system

It happens that methane emission during mining is significantly higher than estimated in the technical project. Therefore, the replacing $\mathrm{U}$ system with $\mathrm{Y}$ system is necessary but generates additional costs.

The Y ventilation system (various types) is used to fight methane hazard. The system is appropriate in coal seams highly saturated with methane; the same applies with prediction of spontaneous heating process in the goaf area or its lack. Also these longwall faces achieve the record level of advance rate and coal output. 
The Y return side ventilation system is used in low thickness seams in hazardous methane conditions. It allows to "move" methane concentration towards goaf from longwall face. After the longwall face is ventilated, the gasses are mixed with fresh air and removed by returning air along the goaf. This system ensures work safety in face area in hazardous methane condition and creates good conditions for methane drainage. It is also useful in case of rock bursts because of three escape routes [5].

\section{Systems of longwall methane drainage}

Methane drainage of rock-mass is the most effective method of controlling methane hazard as it ensures the reduction of methane emission into the working areas. The method that has proved the most efficient is draining methane from rock-mass and goaf area and transporting it to the surface through pipelines, using the depression from drainage station pumps.

Method involves drilling boreholes, called methane boreholes, from tailgate roadway to an unstressed zone in roof or floor layers of a mined seam. The location and parameters of the boreholes depend on the exploitation system and the way of longwall ventilation.

Defining of desorption zone caused by exploitation is necessary during methane drainage of the adjacent coal seams. Drainage boreholes should be situated in stress-relieved zone while not crossing the caving zone. The method of calculating the slope angles of the drainage boreholes, presented in the figure below, produces good results (Fig. 3).

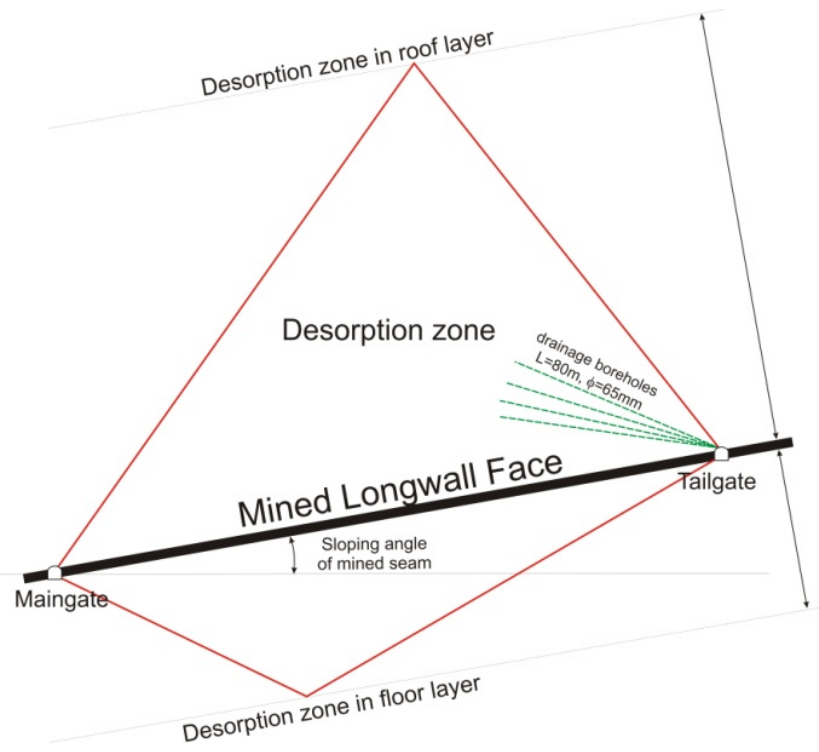

Fig. 3. Determining the methane desorpion zone during longwall exploitation [4]

The location of drilled boreholes is dependent on mining and ventilation systems of longwalls. The highest effectiveness of methane drainage has been achieved by means of Y ventilation system. In case of classic $U$ ventilation system of longwall panel, over time, boreholes drilled from the tailgate road behind the longwall front are lost [5].

Figure 4 presents the drainage system used in Polish mines. An example of drainage system in Vietnamese conditions in Quang Hanh mine, coal seam 7, is shown in Figure 5.

Vietnamese and Polish coal mines employ similar drainage system because of similar geological conditions. Moreover parameters of drainage system and parameters of boreholes are comparable. However, in Vietnamese coal mines the intensity of methane release into the headings is lower because of lower concentration of production. Therefore, the methane 
hazard is usually tackled through ventilation. For this reason, the effectiveness of methane drainage is simply lower.

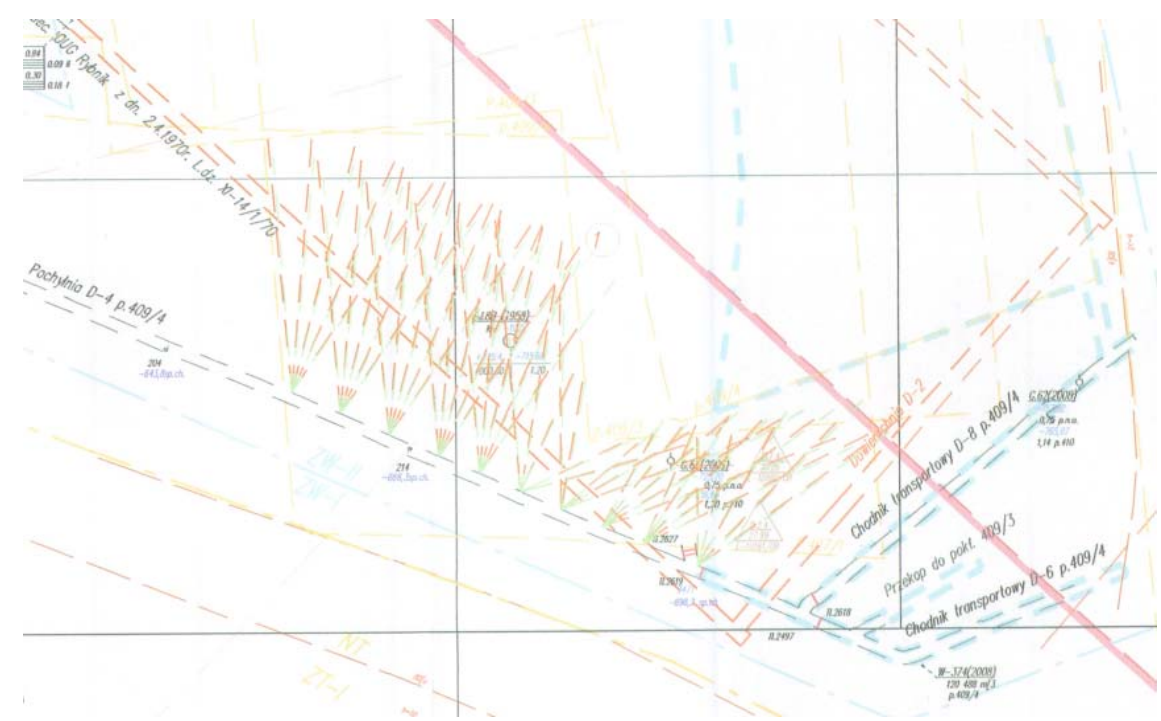

Fig. 4. The sample of boreholes location in Polish mines

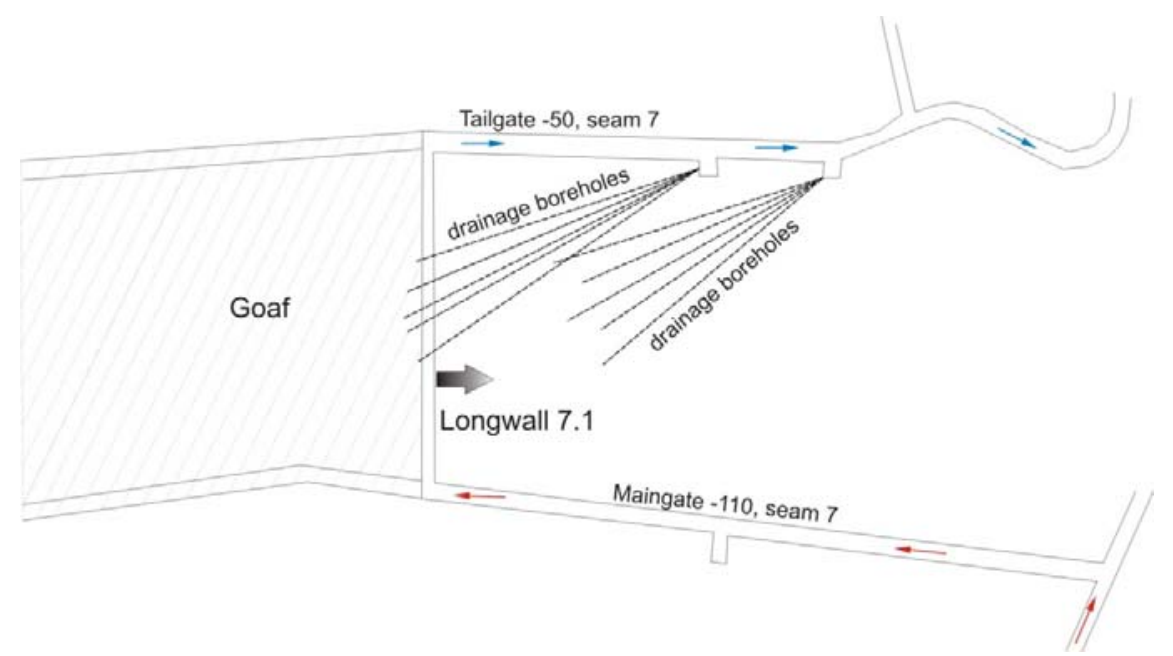

Fig. 5. Scheme of methane drainage for longwall in coal seam 7

\section{Control of methane content in the mine air}

In Vietnam and Poland the specific rules require to maintain the permissible concentration of methane in the mine air. They define moreover, where and how the measures should be taken. The ventilation system of the extracted longwall affects the way of deployment of the methane sensors. While their location relates to mining and geological conditions of the longwall. It also depends on the deployment of the ancillary ventilation devices that prevent accumulation of the dangerous methane $[2,3]$.

Full control of the methane hazard is carried out by:

- the measurement of methane content in longwall, 
- the measurement of methane content in drainage pipelines,

- the measurement of air velocity in longwall,

- control of the closure of ventilation stopping that affect the ventilation of the underground longwall,

- the measurement of other gases (e.g. oxygen, carbon monoxide, carbon dioxide).

The deployment of sensors is close in Vietnamese and Polish mines. However, in Polish conditions due to high concentration of production, the area of longwall working is secured by more different sensors. The sample of the deployment of the methane sensors is presented in Figure 6.

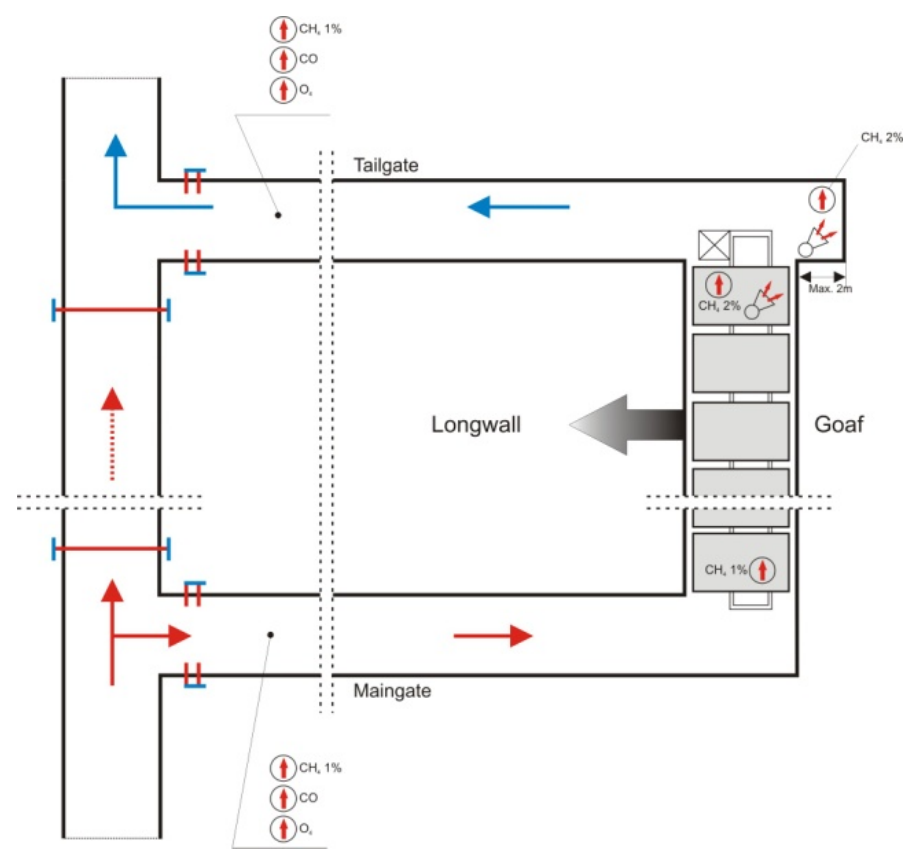

Fig. 6. The scheme of sensors deployment in the longwall

\section{Auxiliary ventilation devices}

The auxiliary ventilation devices are installed in order to protect against the dangerous methane concentration in the point of intersection of longwalls and longwall headings. The most frequently used are wing curtains and jet-fans $[2,3,5]$.

Air injectors are used with low methane risk. Their task is to guide the part of the air from the longwall workings into the goaf. Ventilation using the wing curtains is presented in Figure 7. The effectivness of their use is limited. They are most often used with other solutions that provide protection from methane hazard and owing to that wing curtains efficiency is being increased.

In the event of a greater risk jet-fans are commonly employed. They cause higher air turbulence resulting in good mixing of methane flowing from the caving zone. The examples of jet-fans use is shown in Figure 8. The operating range of the free airflow depends primarily on its initial speed. The efficient operation of the jet-fan is affected mainly by its location and air discharge direction. The methane risk is efficiently eliminated in the case where the air discharge is pointed upwards. Both in Polish and Vietnamese conditions, auxiliary ventilation 
devices are used which together with other measures in the most effective way reduce the methane threat.
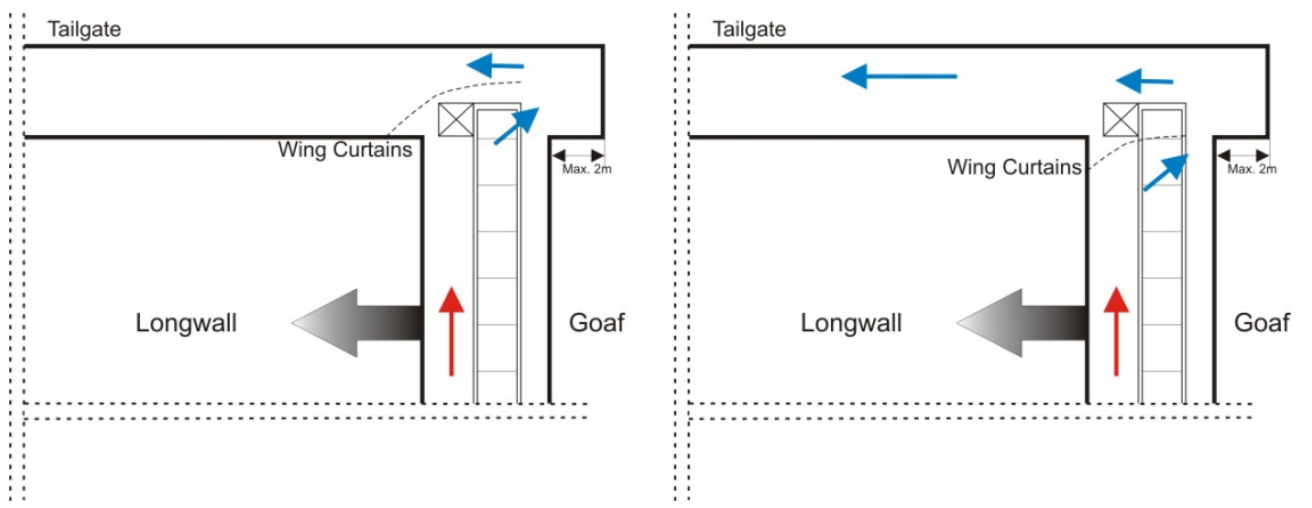

Fig. 7. The ventilation using wing curtains

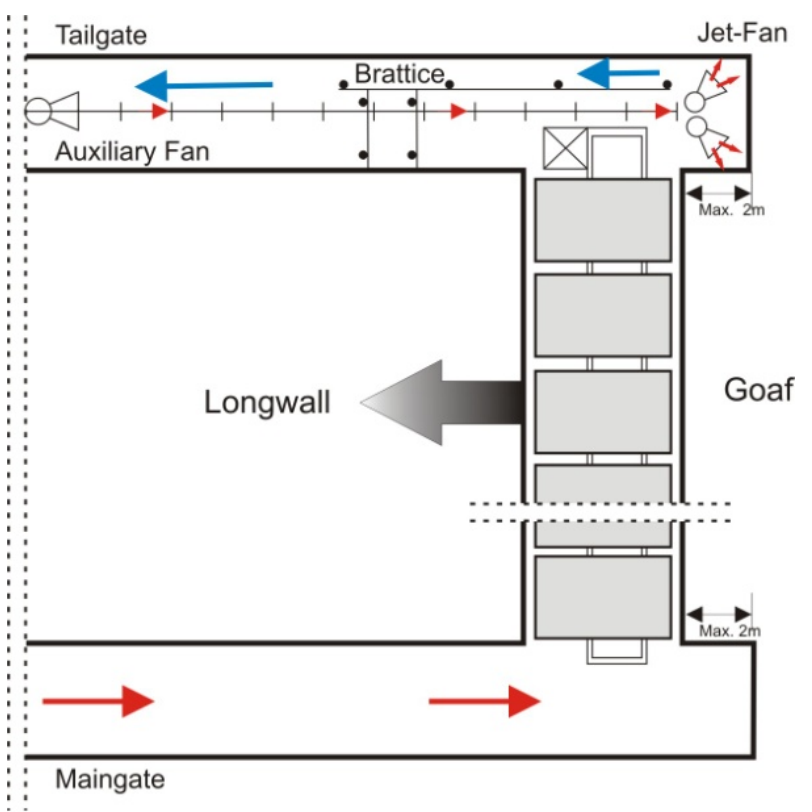

Fig. 8. The examples of jet-fans use

\section{Conclusions}

Prevention actions against the methane hazard comprise recognition, control and combat measures. The main efforts taken by the coal mines are:

- ventilation that prevents the methane concentration,

- methane drainage,

- methanometry that controls the methane concentration in the air,

- auxiliary ventilation devices used in places of high methane concentration.

The first way of fighting the methane hazard is effective ventilation. This involves choosing the proper way of underground working ventilation. The Polish and Vietnamese coal mines 
mainly employ the U ventilation system. However Polish coal mines, because of high concentration of the output, use other methods including Y ventilation system. With methane hazard increasing the methane drainage becomes necessary.

Methane drainage of rock-mass is the most effective method of preventing methane hazard as it reduces the frequency of methane inflows into working areas and prevents or reduces occurrences such as outflows, sudden outbursts of methane and rocks, etc.

The method that has proved the most efficient is draining methane from rock-mass and gobs and transporting it to the surface through separate pipelines, using the negative pressure of drainage station pumps. Although this method ensures the desired parameters of ventilation, it imposes certain requirements concerning the development of methane-bearing coal seams.

To ensure the required efficiency of methane drainage in longwalls, it is necessary to select an adequate system of ventilation and drainage at the design stage of development. Methane is captured with greatest efficiency in drainage boreholes located directly in front of the longwall front; the further a borehole is removed from the front, the smaller the amount of captured methane. When the development front moves further away and the borehole is in the unstressed zone, the amount of captured methane increases to reach its maximum about $30 \mathrm{~m}$ behind the longwall front. At a distance of about $200 \mathrm{~m}$, the capture disappears following the destruction of the borehole. Therefore, effective methane drainage in longwalls is possible only as long as drainage boreholes are situated in a depression. This in turn is possible when a ventilation heading is situated behind the longwall front or the exploitation is conducted using a second ventilation heading. The highest methane drainage efficiency is accomplished by a ventilation system $Y$.

The additional measure of methane hazard control is methanometry system which might be expanded by extra sensors. This system is extended in case of methane at dangerous level or in case of coexistence of fire and rock-burst hazards.

The applied preventive measures might be supplemented by additional devices that shall help to achieve good results but only where using with other solutions.

\section{Acknowledgments}

The article was prepared within the framework of statutory activities 11.11.100.005.

\section{References}

1. M. Borowski: Method of methane emission's prognosis in longwall excavations in coal mines, Wydawnictwa AGH,. Kraków, (2012)

2. C.Ö. Karacan, F. A. Ruiz, M. Cotè, S. Phipps: Coal mine methane: A review of capture and utilization practices with benefits to mining safety and to greenhouse gas reduction. International Journal of Coal Geology 86, pp. 121-156, (2011)

3. F. Kissell (Ed.): Handbook for Methane Control in Mining. Information Circular No: 9486. NIOSH, Pittsburgh, USA, (2006)

4. K. Noack: Control of gas emissions in underground coal mines. International Journal of Coal Geology 35, pp. 57-82, (1998)

5. N. Szlązak, M. Borowski, D. Obracaj, J. Swolkień, M. Korzec: Comparison of methane drainage methods used in Polish coal mines. Archives of Mining Sciences, ISSN 08607001, vol. 59, No. 3, pp. 655-675, (2014) 